\title{
Padrões de acumulação setorial: finanças e serviços nas transformações contemporâneas da saúde
}

\author{
Capital accumulation patterns: capital and services \\ in the current transformations of the health system
}

M aria de Fátima Siliansky de Andreazzi ${ }^{1}$

George Edward Machado Kornis ${ }^{2}$

\footnotetext{
${ }^{1}$ Instituto de Estudos de Saúde Coletiva, Departamento deM edicina Preventiva, UFRJ. Av. Brigadeiro Trompowski, s/no, Praça da Prefeitura da Cidade Universitária, Ilha do Fundão. 21949-900 Rio deJaneiro RJ. siliansky@iesc.ufrj.br ${ }^{2}$ Instituto deM edicina Social, Departamento de Planejamento e Administração em Saúde, UERJ.
}

Abstract The purpose of this article is to introduce elements of the capitalist society economic reproduction to the discussion around the current dynamics of health accumulation. It identifies the direction and significance of capital accumulation in the health area as well as the characteristics of the economic environment where the competition currently takes place. The hypothetic hypertrophy of the financial sphere is seen as a means for structuring the capitalist economy since the late twentieth century. The former delimitations between industrial production and service delivery are blurred and weakened; the competition process shows new features and the contradictions- internally between the different elements of the health industry and externally with other sectors - are changing. This article aggregates elements for a contemporary analysis of the "medical-industrial complex" on the basis of a theoretical-historical-conceptual approach. We identify changes in the capital dynamics of this complex at international and national level and stress the increasing role of the health services as a for efront of capital accumulation. The new approach is based on the economic thinking of M arx in addition to the current discussions about the theory of financial capital accumulation and the new productive configurations of the large corporations.

Key words Political economy of health, M edicalindustrial complex, Growth of financial activities, Healthcare industry, Health insurance.
Resumo 0 objetivo desteartigo éintroduzir elementos da reprodução econômica da sociedade capitalista na avaliação da dinâmica contemporânea da acumulação da saúde. São identificadas a di reção e o sentido da acumulação de capital eo ambiente onde se desenvolvem os atuais processos de competição. 0 trabalho considerou a hipótese da hipertrofia da órbita financei ra como um modo de estruturação da economia capitalista desde 0 último quartel do século XX, onde ficam embaçadas e corroídas antigas delimitações entre produção de bens e prestação de serviços. M udam os padrões decompetição entreas empresas, bem como as contradições internas e externas ao setor saúde. A abordagem é teórico-histórico-conceitual, visando aportar elementos para uma abordagem contemporânea do tema "complexo médico-industrial". São identificadas transformações internacionais e nacionais referentes à dinâmica do capital no complexo, com destaque para 0 crescente papel dos serviços. A nova abordagem éelaborada a partir do pensamento econômico de M arx, acrescido da discussão contemporânea sobre financeirização e novas configurações produtivas da grande empresa. Ao final, o caráter das contradições existentes no interior do complexo produtivo da saúde é problematizado.

Palavras-chave Economia política da saúde, Complexo médico-industrial, Expansão da esfera financei ra, Serviços de saúde, Seguros de saúde 
Essas mudanças na performance refletem uma auto-compreensão da indústria do seguro saúde como um setor maduro onde o crescimento dos ganhos ao invés do crescimento das coberturas éa medida do sucesso. Wall Street estimulou e celebrou esta mudança de foco.

Robinson $^{1}$

Introdução

0 objetivo desteartigo éintroduzir elementos do processo mais geral de reprodução econômica da sociedade capitalista na avaliação da dinâmica contemporânea da acumulação setorial da saúde. No texto, procuramos identificar a direção e o sentido de acumulação do capital e também perceber 0 ambiente onde se desenvolvem os atuais processos de competição. 0 trabalho depesquisa considerou, especificamente, a hipóteseda hipertrofia da órbita financeira ser, já desde o último quartel do século $X X$, um modo de estruturação da economia capitalista. N esse novo quadro, no qual estão embaçadas e corroídas antigas delimitações entre produção de bens e prestação de serviços, mudam os padrões de competição entreas empresas, bem como as contradições internas e externas ao setor saúde.

Esse artigo, de caráter histórico-conceitual, é uma etapa preliminar deum trabalho onde, posteriormente, a sistematização e análise de dados empíricos será de importância capital. Trata-se, portanto, de um texto que visa aportar elementos para uma abordagem contemporânea do tema "complexo médico-industrial (CMI)".

A presente etapa está composta por três segmentos seguidos de um epílogo. 0 primeiro retoma as formulações originais da década de 1970 acerca do CM I. No segundo segmento, é discutida, segundo diferentes óticas interpretativas, a hipertrofia do setor serviços, com destaque para a dos serviços financeiros. Finalmente, no terceiro segmento, são aportados alguns elementos para uma renovada abordagem teórico-conceitual do complexo médico-industrial, no quadro das mudanças sistêmicas do capitalismo contemporâneo.

O complexo médico-industrial: das origens às formulações atuais

Desde os anos 70 do século passado, analistas do setor saúde utilizam o conceito de complexo médico-industrial para explicar as inter-relações entre a prestação de serviços de saúde e a indús- tria de bens necessários à provisão de cuidados em saúde. Sua origem pode ser encontrada no interior do pensamento crítico do modelo desaúde norte-americano nos anos 1970. Segundo Waitzkin², o "complexo militar-industrial", articulação de interesses entre o setor estatal de defesa estadunidense e a indústria de armamentos, forneceu um modelo de penetração industrial para o sistema de saúde e popularizou o termo "complexo médico-industrial". Relman ${ }^{3}$, em 1980, analisando as transformações dos serviços de saúde, identificou movimentos do grande capital para o interior do segmento, configurando um novo complexo médico-industrial.

Cordeiro ${ }^{4}$ é a referência pioneira quando se trata do conceito CM I no Brasil. Essa referência incorpora matrizes teóricas mais amplas do que as matrizes originais norte-americanas. Nesse sentido, ele assimila tanto as formulações de corte tradicional marxista, como também incorpora criticamente elementos de autores afeitos a outros referenciais teóricos (tais como llitch e Dupuy \& Karsenty). 0 aprofundamento da análise sobre o consumo de medicamentos permitiu identificar um aspecto crítico para a indústria produtora desses bens na criação de necessidades sociais de consumo e na influência sobre a prática médica.

No seu trabalho de $2006^{5}$, esse autor atualiza a sua reflexão sobre o papel dos serviços de saúde dentro do processo de acumulação de capital, nos seguintes termos:

. Como serviços não destinados à circulação de bens materiais, permitiriam ou facilitariam 0 consumo de qualquer valor de uso, ou seja, que constitua a efetiva realização da utilidade das mercadorias ou da utilidade do trabal ho.

. Os serviços não possuiriam, em sentido estrito, um valor de troca.

. O processo de trabalho compreendido no serviço "stricto sensu" produz um determinado valor de uso que, ao ser despendido, é imediatamente consumido. É, portanto, incapaz de criar mais-valia. 0 trabalho empregado na produção de serviços médicos não deriva seu lucro de uma função econômica imediata, mas sim, o obtém pela repartição e transferência, para sua órbita, de uma parcela da mais-valia global produzida, a título de remuneração de serviços. 0 empresariamento nos serviços seria uma variante do capital mercantil.

Uma conseqüência da dinâmica da acumulação em saúde, a partir da constituição do complexo médico-industrial, foi o crescimento do custo unitário da atenção médica, percebido nos 
Estados U nidos, já desde a década de 1950, e diretamente associado à intensidade e rapidez de incorporação e obsolescência da tecnologia ${ }^{6}$. 0 outro lado da moeda foi o quanto 0 aumento desse custo interferiu no lucro das empresas eno gasto das famílias.

Além da indústria e dos serviços médicos, ocorreu a introdução de um terceiro ator representado pelos financiadores privados que amplia a complexidade do processo de acumulação. M ovimentos de grandes empresas de seguros para a cobertura de atenção à saúde já estavam bem estabelecidos nos Estados Unidos desde os anos 1950.

Gastos crescentes com saúde são um fato presente desde então, mas eles só se tornam problemáticos quando se dá o esgotamento do ciclo expansivo da produção duas décadas mais tarde. Antes dessa inflexão na economia mundial, a inflação médica, nos Estados Unidos, era imediatamente repassada ao preço dos prêmios dos seguros, que funcionavam, majoritariamente, como intermediadoresfinanceiros. 0 crescimento deum setor médico-empresarial distinto do mercado tradicional de seguros, voltado para o planejamento e controle dos gastos em função de seu papel de prestador associado ao de segurador, foi considerado, inicialmente, capaz de reverter a inflação médica. Esse novo setor, nos Estados Unidos, foi denominado M CO (M nanaged Care Organizations) e, no Brasil, empresas médicas de pré-pagamento. U ma atenuação da velocidade de crescimento da inflação médica nos Estados Unidos, a partir da implantação da atenção gerenciada nos anos 1980, éreconhecida pela literatura acadêmica ${ }^{7}$. Na primeira década do século XXI, entretanto, essa tendência parecenão mais se manter.

Robinson ${ }^{1}$, entre outros autores, identifica, a partir de 2000, uma redução nas coberturas de seguro saúde dos empregadores. Essa redução logrou ser contrabalançada pelo discreto aumento da filiação individual e, fundamentalmente, pelos incentivos públicos contidos nas reformas queforam introduzidas, em 2003, no M edicareseguro de saúde administrado pelo Estado norte-americano para maiores do que 65 anos. Essas reformas introduziram um ben efício farmacêutico, porém, vinculando-o somente àqueles beneficiários inseridos em planos de saúde privados. Vale observar que teve também um papel relevante o maior aporte do M edicaid - programa de cobertura pública de saúde a populações incapacitadas de adquirir seguros privados, seja individualmente ou através do empregador - às empresas de managed care. Esse autor também informa que "As principais firmas... aumentaram continuamente os prêmios acima dos custos... expandindo margens e receitas" ${ }^{11}$.

Resulta das transformações ocorridas no setor saúde, um aumento da diferenciação social dos produtores, fruto de novas relações de produção que se somam às antigas, ainda remanescentes, como a reduzida prática liberal de profissionais de saúde. Portanto, acentuam-se e modificam-se os padrões de competição entre os diferentes capitais atuantes no setor saúde.

No Brasil, essa perspectiva de complexo para a análise do setor saúde foi, em 2002, reincorporada em novas bases teóricas e históricas por Vianna ${ }^{8}$. Esse autor identifica, em um novo quadro conjuntural, a presença de [...] dois atratores fundamentais moldando o comportamento deseus agentes. U m é a tecnologia e outro é 0 aspecto financeiro de valorização do capital. Para o primeiro constitui-se o que se denomina complexo médico-industrial, enquanto que, para o segundo, tem-se o aparecimento de um complexo médicofinanceiro [...]"8. 0 primeiro se constituiria no grande vetor da expansão dos gastos em saúde. O segundo, composto, fundamentalmente, pelo capital financeiro, onde 0 autor inclui um capital financeiro público, estaria interessado, ao contrário do primeiro, em um processo de racionalização dos gastos em saúde. Reconhece Vianna ${ }^{8}$, entretanto, a diversidade de atores e interesses envolvidos, bem como a dificuldade de previsão dos resultados, o que nos remete à necessidade de um maior entendimento da conjuntura onde se movem esses agentes.

Um outro autor brasileiro relevante nesse debate é Gadelha' ${ }^{9}$ o qual incorpora o conceito de complexo industrial da saúde em outras bases teóricas, como [...] "conjunto interligado de produção de bens eserviços em saúde quese movem no contexto da dinâmica capitalista [...]". A problemática principal do autor éa possibilidade do segmento industrial do complexo, a partir de demandas do Estado e dos serviços de saúde, alavancar processos de geração de emprego, renda e riqueza. No seu trabalho de 2006, Gadel ha ${ }^{10}$ torna mais explícita essa perspectiva que, no Brasil, passaria pela redução da dependência de produtos importados. Identificamos, nesse autor, uma forte influência do pensamento cepalino na priorização do desenvolvimento econômico nas condições de um capitalismo periférico.

Albuquerquee Cassiolato ${ }^{11}$ eAlbuquerque et al. ${ }^{12}$ também recuperam o conceito deCM I como uma articulação de setores industriais, de servi- 
ços e formação, destacando as interações entre esses setores para o desenvolvimento de inovações. Esses autores chamam a atenção para a fragilidade da difundida concepção que associa as inovações em saúde aos custos da assistência médica, pois muitas inovações possuem uma eficácia e efetividade significativas, reduzindo a incidência, prevalência e letalidade das enfermidades. N esse segmento, estariam as inovações de alta tecnologia, como as vacinas, técnicas de diagnóstico e terapia menos invasivas e medicamentos mais eficazes, que reduziriam a duração da permanência em hospitais. Além disso, eles destacam a ênfase atual na promoção da saúde, tanto ao nível coletivo quanto individual e no desenvolvimento de equipamentos biomédicos de menor tamanho e custo. Esses autores, assim como Gadelha ${ }^{10}$, atribuem ao Estado um papel decisivo no direcionamento das inovações a partir deum perfil denecessidades de saúde. Guimarães ${ }^{13}$ também reconhece que " $A$ articulação entre os sistemas nacionais de inovação e o aumento do bem-estar e a inclusão social é um terreno a ser ainda explorado".

Dado que o conceito de CMI tem sido, na atualidade, revigorado no Brasil, consideramos pertinente identificar mudanças recentes no seu interior que possibilitarão delimitar fronteiras possíveis de expansão de estudos nesse campo temático. E que mudanças históricas são essas a suscitar novos desenvolvimentos teóricos? Ainda que de modo preliminar, identificamos nos segmentos do CMI indícios que conduzem a essa possibilidade.

$\mathrm{Na}$ perspectiva do capital produtivo industrial, a par da permanência, desde os anos 1950, do caráter altamente concentrado e intensivo em capital, observamos a presença de um renovado ciclo de fusões e aquisições com o conseqüente aumento da concorrência entre os grandes grupos farmacêuticos mundiais que constitui um relevante fato novo da década de 1990. M agaIhães et al. ${ }^{14}$ crêem que isso sugere que a busca por economias de escala e escopo em pesquisa e desenvolvimento, por redução dos custos de marketing ede distribuição epelo fortalecimento do portfolio de produtos, foi um fator importante para a concretização desse processo. Segundo esses autores, também deve ser considerada a criação de expectativas positivas de ganhos financeiros com as operações de fusões e aquisições. Eles acrescentam quenos anos 2000 foi identificada uma diversificação dos players com um desenvolvimento importante de firmas originárias de países de fora da tríade (Estados U nidos,
Europa eJapão) como, por exemplo, a Índia. No Brasil, trabalhos publicados na coletânea organizada por N egri e di Giovanni ${ }^{15}$ e também Hasenclever ${ }^{16}$ destacam a ainda presente dependência externa, no tocante a fármacos e equipamentos biomédicos sofisticados. Entretanto, nessa mesma década, Gadel ha ${ }^{10}$ identifica uma relativa melhora na balança comercial decorrente de esforço exportador da indústria nacional de equipamentos biomédicos.

No prisma do capital mercantil de seguros, destaca-se o crescimento de inovações tais como as contas individuas de saúde (health saving accounts) ${ }^{17}$. Estas atuam como uma maneira distinta de aumentar a participação individual dos consumidores no financiamento de coberturas de saúde, para além dos co-pagamentos e franquias. No Brasil, após a estabilização da economia, as seguradoras estabeleceram outras estratégias para aumentar seu lucro comercial, a partir de uma maior integração e controle dos prestadores de serviços ${ }^{18}$.

No tocante aos serviços de saúde, acentuouse a sua heterogênea configuração com relações de produção variadas que vão desde o profissional liberal, até as grandes empresas do setor saúde. O correu um crescimento de multinacionais de prestação de serviços, como a Frensenius, de capital germânico, formada pela diversificação da indústria de equipamentos ${ }^{19}$.

$\mathrm{Na}$ perspectiva dos processos produtivos, cabe destacar a extrema diferenciação dos produtos decorrente das variadas combinações entretrabal ho, conhecimento especializado emeios de produção (equipamentos, materiais e medicamentos). No Brasil, os serviços de saúde, a partir dos anos 1990, têm mostrado tendências que amplificam a heterogeneidade do ponto de vista do processo de acumulação, o que trouxe mudanças nas relações de produção e no grau de influência do capital financeiro. Em pesquisa realizada por Andreazzi ${ }^{20}$, em 2002, foram identificados movimentos de fusões, com a participação de capital internacional, particularmente em São Paulo, região de maior concentração de beneficiários de seguros privados de saúde. A International Finance Corporation (IFC), braço do Banco M undial quefinancia o setor privado, bem como outros fundos de investimento, inclusive fundos de pensão nacionais, estiveram presentes nesses movimentos de aquisições e fusões. Expressam esse processo de concentração a presença do Grupo Vita, do Latin H ealth Fund, da I catu H ealth Services, do Grupo São Luís e da Seguradora AIG que se associou a uma rede de far- 
mácias. Estas tendências se mantêm, pois investimentos hospitalares recentes no Rio de Janeiro contam com a participação de fundos de investimentos e fundos de pensão.

O mercado de patologia clínica, desdeos anos 1980, quiçá seja um dos melhores exemplos das intensas transformações por que têm passado alguns serviços, com a introdução de novos instrumentos e técnicas de produção e sua concentração nas mãos de poucos proprietários. Estas mudanças introduziram no processo de produção do laboratório uma maior produtividade, permitindo que houvesse retornos crescentes de escala e, por conseguinte, criando barreiras à entrada, por capitais fixos iniciais el evados.

Quais são os elementos da conjuntura do início dos 2000 que poderiam estar associados a essas mudanças? Quais categorias teórico-conceituais podem nos ajudar desvendar as contínuas mutações em curso tanto no interior do CMI quanto nas relações do CMI com o conjunto da economia? A seção seguinte procurará destacar as principais mudanças na dinâmica do capitalismo contemporâneo em suas inter-relações com o setor saúde.

A mundialização do capital ea expansão dos serviços

Os anos 1990 foram marcados pelo fenôme no conhecido como globalização ou mundialização do capital ${ }^{21}$. Tal processo se intensifica nos anos 2000 tendo, como uma de suas principais conseqüências, a contínua hipertrofia do setor financeiro. A esfera financeira seria formada por um conjunto de transações e instituições especializadas, num circuito de autovalorização sem contrapartida ao nível da produção. A presença dessa esfera não real sugeriu a $\mathrm{M}$ ar $\mathrm{x}^{22}$ a utilização do conceito de "capital fictício". N o entanto, é importante destacar que "Os capitais que os operadores financeiros põem para valorizar...nasceram invariavelmente do setor produtivo [...]"23. A financeirização conformaria um novo ambiente competitivo que traz impactos significativos para as empresas. De acordo com Chesnais ${ }^{23}$ uma característica da mundialização foi a notável concentração de capital, sob a hegemonia dos países centrais. 0 capital, no processo de competição por uma demanda decrescente, assume formas distintas da grande empresa multinacional integrada verticalmente e departamentalizada, que foi a dominante desde o final do século XIX. O predomínio do aspecto financeiro da acumulação de capital favorece a concentração e esta intensifica a escala da acumulação de capital. As grandes empresas produtivas, além de contarem com uma forte área financeira - bancos tradicionais ou novas instituições financeiras - se concentram nos aspectos mais estratégicos da produção - tecnologia e desenho do produto - eatuam de modo crescentemente descentralizado na montagem de produtos e nas vendas. Dupas ${ }^{24}$ identifica que, no quadro da nova dinâmica do sistema capitalista, seria mais difícil estabelecer fronteiras nítidas entre indústria, serviços em geral e serviços financeiros. 0 produto financeiro "seguro", por exemplo, também passa a ser oferecido por grandes corporações, na origem, industriais.

Assim, [...] Os grupos industriais tendem a organizar-se como "empresas rede". As novas formas de gerenciamento e controle, valendo-se de complexas modalidades deterceirização, visam ajudar os grandes grupos a reconciliar a centralização do capital e a descentralização das operações, explorando as potencialidades proporcionadas pela teleinformática e pela automação [...] 0 grau de interpenetração de capitais de diferentes nacionalidades aumentou. 0 investimento internacional cruzado e as fusões-aquisi ções transfronteiras engendram estruturas de oferta altamente concentradas, a nível mundial23. As grandes empresas do capitalismo contemporâneo externalizariam os riscos associados à demanda instável e os desgastes de imagem e problemas legais associados à informalização do trabalho, sonegação fiscal e agressão ao meio-ambiente ${ }^{24}$. Os terceirizados, ao prestarem serviços exclusivos para as empresas que nucleiam a rede, não teriam a autonomia de produção e venda de seus produtos num mercado competitivo. Dupas ${ }^{24}$ afirma que o espaço econômico mais provável destinado às pequenas emédias empresas (easnacionais) seriam as franquias, terceirizações esubcontratações, subordinadas às decisões estratégicas das transnacionais e integradas às suas cadeias produtivas. É interessantenotar que Hilferding ${ }^{25}$, já em 1909, identificava este processo: “ [...] Uma grande parte dos estabelecimentos pequenos se converteram em auxiliares das grandes empresas [...] são só independentes em aparência".

Nos anos 2000, Chesnais $s^{26}$ identifica particularidades dentro do processo de mundialização do capital: O capital portador de juros está localizado no centro das relações econômicas e sociais. Asformas deorganização capitalista maisfacilmente identificáveis permanecem sendo os grupos industriais transnacionais, os quais tem por encargo or- 
ganizar a produção de bens e serviços, captar o valor e organizar de maneira direta a dominação política e social do capital em face dos assalariados. M as ao seu lado, menos visíveis [...] estão as instituições financei ras bancárias, mas sobretudo as não bancárias [...] Esse capital busca fazer dinheiro sem sair da effera financeira [...] sob a forma de [...] lucros nascidos da especulação bemsucedida. Dentre essas instituições, encontram-se as sociedades seguradoras, mas a sua participação na posse de ativos, a partir do final dos anos 1990, éreduzida favorecen do as sociedades deinvestimento e os fundos de pensão. Desta forma, as empresas tornam-se ativos, cujos detentores não seriam mais credores, mas sim, elementos exógenos à produção. As finalidades desses agentes seriam o rendimento ampliado, o quetraz para as empresas o imperativo de uma taxa de retorno elevada, acentuando a busca de formas mais intensas de extração de mais-valia. Plihon ${ }^{27}$ assinala que a taxa do rendimento do capital seria fixada a priori segundo benchmarks levando os grupos produtivos a encerrar as atividades de unidades menos lucrativas e a forçar uma recentralização nas atividades nucleares das empresas.

Um outro elemento importantedessa nova etapa do capitalismo seria a terciarização, entendida como a atual importância do setor terciário como gerador de produto e mobilizador de força-detrabalho, que caracteriza não só os países industrializados, mas também aqueles países de industrialização mais recente. Chesnais ${ }^{23}$ deixa claro que o setor de saúde privado torna-se uma das prioridades para o investimento produtivo, tal como telecomunicações, mídia eserviçosfinanceiros.

O complexo produtivo da saúdeengloba processos tanto industriais, como financeiros, além da prestação de serviços diretamente aos consumidores. Portanto, integra, além das indústrias, a produção terciária, que inclui uma grandevariedade de atividades, com especificidades em termos de trajetória e dinâmica de mercado, o que fragiliza a generalização conceitual ${ }^{28}$. I dentificar o papel que representa o terciário, na atualidade, no processo deacumulação de capital é requisito necessário para o real entendimento das transformações contemporâneas operadas no interior do CMI.

As implicações do processo de expansão se tor serviços para dinâmica capitalista como um todo é objeto de controvérsias. A literatura sobre o tema é relativamente recente e pequena, mesmo internacionalmente, e concentrada em torno de alguns aspectos. No Brasil, Kon ${ }^{29}$, em trabaIho de síntese, destaca a importância tanto da discussão do papel dos serviços no desenvolvimento econômico, quanto do entendimento de suas relações com as inovações tecnológicas, com a reestruturação produtiva e, finalmente, com a terceirização. Essa autora identifica uma diversidade de análises cujo ponto focal é a criação de valor por parte do setor serviços.

A concepção tradicional do setor serviços parte dos economistas clássicos quando a importância do setor serviços não tinha ainda se afirmado.

No pensamento neoclássico moderno, destaca-se Baumol ${ }^{30}$ que, no seu trabalho de 1967, associa o crescimento de uma parcela significativa do setor serviços a uma perda do bem-estar social. Essa perda seria decorrente da pressão altista dos salários desse setor que acompanhariam os aumentos salariais dispensados aos trabalhadores industriais, mas não a sua produtividade, gerando o que ele designa por "doença de custos". A baixa produtividade seria por ele atribuída às características tecnológicas da produção de serviços nos quais a qualidade é julgada pela quantidade de trabalho despendida. Como conseqüência, os custos e preços relativos tenderiam a aumentar, bem como a participação das despesas dos consumidores dirigidas para a prestação de serviços. Essa baixa produtividade do setor repercutiria na estagnação do crescimento das economias capitalistas, observada empiricamente a partir dos anos 1970.

No entanto, em uma revisão posterior de seu trabalho, Baumol, em conjunto com Blackman e Wolff ${ }^{31}$, já identificam, a partir de dados empíricos, uma heterogeneidadeno setor serviços, quanto à produtividade, em que se poderiam encontrar, simultaneamente, os setores mais progressistas e os mais estagnados. Suas conclusões anteriores, portanto, não seriam generalizáveis. Esses autores, no entanto, continuam a admitir que "[...] na soma, a doença de custos dos serviços estagnados devem afetar mais da economia do que foi previamente pensado" ${ }^{31}$.

No pensamento da escola regulacionista francesa, o tema é tratado, especialmente, por autores, tais como Gadrey ${ }^{32}$ que analisaram as novas configurações produtivas a partir da crise do fordismo e do papel da financeirização da economia. A nova configuração da grande empresa e a prática disseminada de terceirizações tornaria mais complexa uma pretensa dualidade da indústria, identificada com a alta produtividade versus os serviços, por sua vez identificados com a baixa produtividade. Gadrey ${ }^{32,}$,ao contrário, aponta para uma complementaridade atual no 
consumo e na produção entre esses dois setores. A formação de complexos integrados indústriaserviços, como o complexo médico-industrial, representaria uma nova articulação produtiva. Esses complexos poderiam também representar uma diversificação da própria indústria, tendência contrária aos padrões homogêneos da ante rior forma prevalente de produção: o fordismo.

Assim, os serviços passariam a fazer parte das estratégias de competição das indústrias. Escoariam, inclusive, a produção de bens industriais, o queocorrenão apenas com a saúde. Ade mais, o setor prestador de serviços não apresentaria uma homogeneidade, sendo que as suas partes mais dinâmicas seriam voltadas para clientes empresarias (informática e telecomunicações). Tais teses são denominadas neo-industriais. Para Gadrey ${ }^{32}$, ao se analisar estes dois ramos da produção, a indústria e os serviços, haveria que se identificar as duas coisas: concorrência ecomplementaridade. A crescentedemanda por serviços por parte das empresas industriais poderia significar a redução do risco e incerteza face à conjuntura de demanda decrescente.

A complementaridade indústria-serviços é também percebida por Chesnais ${ }^{23}$ : [...] A contraposi ção entre o setor industrial e os serviços está sendo, então, fortemente abalada, tanto pelos serviços "invadindo" o setor manufatureiro, como pela indústria, cujas companhias, por sua vez, estão se diversificando no sentido dos serviços [...] uma interpretação inicial do interesse que os grupos industriais têm pelos serviços, a ponto de neles investirem, no exterior, de forma bastante vultosa. Dois elementos parecem atuar simultaneamente: 1) o domínio queesses querem manter sobreaspectos complementares dos quais dependeparteda rentabilidade de suas operações; 2) o lugar que certos serviços continuam ocupando, em relação ao movimento total de valorização do capital ${ }^{23}$.

Nos anos 1970, nos países desenvolvidos, as atividades de serviços teriam passado por processos organizacionais semel hantes à industrialização. Na década seguinte, as tecnologias informacionais, que permitiram uma produção industrial competitiva descentralizada, diversificada e mais adaptada à demanda, são também incorporadas ao próprio setor de serviços, facultando, especialmente, grande grau de acesso aos mercados financeiros. A tendência, segundo $\mathrm{Ga}$ drey $^{32}$, seria para uma maior oferta de soluções globais - bens e serviços.

$\mathrm{H}$ ardt e N egri ${ }^{33}$, numa abordagem neo-marxista, destacam um elemento importante da produção contemporânea que éa informatização da produção que eles também chamam de pósmodernização. Essa foi acompanhada, nos países centrais, pela migração do trabalho da indústria para os serviços. Os suutores em pauta, entretanto, reconhecem que essa migração ocorrida nos países centrais foi acompanhada por uma deslocalização do trabalho industrial para a periferia do sistema. M igração que não incluiu as dimensões de controleeinovação, que compõem o trabalho imaterial, que se mantêm fortemente concentradas nos países centrais. Vale observar que essas dimensões são elementos decisivos para a extração de valor dos países periféricos através das contas de serviço. Assim, a descentralização e dispersão global dos processos e lugares de produção, características da pós-modernização e da informatização da economia, provocam uma centralização correspondente do controle sobre a produção. 0 movimento centrífugo de produção é equilibrado pela tendência centrípeta do comando. Serviços financeiros e serviços voltados para os negóci os em cidades-chave administram e dirigem as redes globais de produçãa $0^{33}$.

Tal perspectiva permite a deslocalização da produção não apenas industrial, mas dos próprios serviços. 0 passo seguinte para 0 desenvolvimento do setor serviços dos países centrais, na conjuntura da mundialização, tem sido a internacionalização das empresas de serviços ${ }^{34}$. 0 comércio internacional de serviços após os anos 1980, embora representasse menos do que $30 \%$ do total do comércio de bens, tem apresentado uma taxa de crescimento significativa ${ }^{21,29}$. Em meados dos anos 1990, os investimentos diretos em serviços representaram $40 \%$ do total, no qual a principal parcela coube aos serviços financeiros. Um marco do processo foi o ano de 1995, onde foi assinado o Acordo Geral de Comércio de Serviços (GATS), através do qual os países signatários comprometeram-se a uma progressivaliberalização de seus mercados internos ${ }^{35}$. No entanto, existi riam diferenças significativas entre os tipos de serviços quanto aos acordos de liberalização, ondea saúdee a educação ainda estariam entre os menos representados.

Elementos para uma abordagem ampliada do complexo médico-industrial

A dinâmica contemporânea do capitalismo, onde a financeirização e o crescimento dos serviços se tornam elementos centrais na avaliação da acumulação setorial da saúde, também induz a perguntar se o campo de análise marxista, que teve 
uma forte influência na concepção do complexo médico-industrial, teria como enriquecê-lo. $\mathrm{Na}$ medida em que mudanças históricas estimulam o desenvolvimento das concepções teóricas, podemos sugerir que as mudanças no campo conceitual deveriam necessariamente incorporar as transformações por que passam os serviços, com foco no setor financeiro, na primeira década do século XXI.

Existem, certamente, dificuldades de encontrar nos trabalhos econômicos de M arx afirmações mais categóricas sobrea dinâmica capitalista no setor serviços em função do ainda incipiente desenvolvimento do denominado "domínio da produção imaterial", no final do século XIX. Nessa época, a importância econômica desse setor era restrita aos transportes e comunicações. É possível identificar, entretanto, em algumas passagen s de sua obra, reflexões, ainda que pontuais, que procuram analisar as mudanças nas relações de produção de serviços queestavam já em curso. No Livro 4 de "O Capital"36, a produtividade do capital éentendida como a capacidade de coerção para a obtenção de trabal ho excedente: [...] Capital emprega trabalho. Não são meios para o trabaIhador gerar produtos, seja na forma de meios de subsistência imediatos, seja na de meios de troca, na de mercadorias. Ao contrário, o trabalhador é para eles meio tanto de conservar o valor, quanto de criar mais-valia, isto é, serve Ihes para o acrescer, para sugar trabal ho excedente ${ }^{37}$.

Segundo M arx, troca de dinheiro por serviço, relação simples de produção de valores-deuso, não seria trabalho produtivo (por exemplo, a contratação de um alfaiate para fazer uma calça). A troca, nesse caso, ao invés de produzir capital, "é dispêndio de renda" ${ }^{37}$. Quando determinado ramo de produção passa a ser depositário de relações de produção capitalistas (força-detrabalho que se defronta com capital), há produção de capital, como valor que produz maisvalia, como valor que acresce. Isso ocorreria a partir da expansão de relações capitalistas para todo gênero de produção pois Quanto mais se desenvolvea produção em geral como produção de mercadorias, fazer dinheiro quer com o seu produto, quer com os seus serviços - quando o seu produto, devido à sua natureza, só existe sob a forma de serviço - e esse fazer dinheiro aparece como 0 objetivo ultimo de todo gênero de atividade ${ }^{37}$.

Essas afirmações estão afeitas à esfera da produção e não à da circulação onde o capital assume a forma particular de capital mercantil. No entanto, a discussão acerca do trabalho produtivo ou improdutivo está presente, também, no âmbito do capital mercantil, poisno processo global de reprodução, o capital industrial e o capital mercantil são formas diferenciadas de existência do mesmo capital. A função comercial, ao se tornar autônoma face à produção, torna-se objeto deum investimento especial decapital: $N$ o processo de circulação não é produzido valor, portanto, tampouco mais-valia. Ocorrem, apenas, mudanças deforma da mesma massa devalor ${ }^{22}[\ldots]$ À medida que contribui para encurtar o tempo de circulação, pode ajudar a aumentar, indiretamente, a maisvalia produzida pelo capitalista industrial. À medida que ajuda a ampliar o mercado e medeia a divisão do trabalho entre os capitais, portanto capacita o capital a trabalhar em escala mais ampla, sua função promove a produtividade do capital industrial e sua acumulação. À medida que encurta o tempo de circulação, eleva a proporção de maisvalia para o capital adiantado, portanto a taxa de lucro ${ }^{22}$. Para o capitalista comercial, a exploração da força-de-trabalho teria a função de rebaixar os custos de produção assim como o trabalho nãopago do trabalhador cria diretamente mais-valia para o capital produtivo, o trabalho não-pago do trabalhador assalariado comercial cria para o capital comercial uma participação naquela maisvalia ${ }^{22}$. M arx, mais adiante, constata a pugna que existe entre esses dois setores autonomizados da reprodução global do capital, quando afirma que "Quanto maior o capital comercial em relação ao capital industrial, tanto menor a taxa de lucro industrial e vice-versa" 22 .

Acreditamos que não é a natureza do produto (sematerial ou imaterial) que definea existência ou não da acumulação capital ista esim a transformação do trabalho em força produtiva do capital onde os meios de produção apresentamse, essencialmente, como meios para a exploração do trabalho al heio. Posição semel hanteéapresentada por Silva eM eirelles ${ }^{38}$ quando afirma que De modo contrário a Smith, para $M$ arx não é a materialidade do produto que define se determinada atividade econômica éou não produtiva, isto é, se ela agrega ou não valor, pois a relação de compra e venda não é uma relação entre objetos e coisas, e sim uma relação social. N esta perspectiva, a definição de trabalho produtivo se dá deforma independente do conteúdo material e tangível da mercadoria ${ }^{38}$.

Afirma, ainda, $\mathrm{M}$ arx ${ }^{22}$, a existência de uma tendência à equalização da taxa de lucro entre os diferentes segmentos da produção e da circulação. A introdução de um ramo novo permitiria aos primeiros produtores auferir lucros muito acima do lucro médio, o que atrairia outros ca- 
pitais que, por força da concorrência, acabaria por equalizar a taxa de lucro. Esse fato seria contra-arrestado pela universalização da competição oligopolista que tenderia a cristalizar essas diferenças ${ }^{39}$.

0 debate em torno da possibilidade dos serviços poderem ou não criar valor tem implicações sobre o papel do terciário para o desenvolvimento capitalista contemporâneo. Trata-se, portanto, deum debatequetem atualidade erel evância. A interpretação de que o ramo de produção de serviços de saúde integra o capital mercanti ${ }^{5}$ não invalida, no entanto, a possibilidade do setor serviços reter na sua esfera parcelas importantes de mais-valia, se tornando uma área de interesse para a expansão da acumulação de capital.

A ampliação de relações de produção capitalistas nos serviços de saúde e a concentração do capital chegam, mais tardiamente, a esse segmento do complexo produtivo da saúde. Acentua-se, desse modo, a pugna pela parcela da mais-valia que circula entre os segmentos do complexo indústria, serviços, seguros. As diversas formas de integração no interior dessa cadeia produtiva passam a contar nas estratégias de competição das empresas, favorecendo e sendo favorecidas pela centralização de capitais.

No interior do CMI, as relações entre indústria e serviços e, em particular, serviços financeiros podem assumir um caráter antagônico e/ou complementar entre os componentes médicoindustrial emédico-financeiro.

Vale reiterar que, no caso da complementação, o serviço de saúde garantiria o escoamento da produção da indústria, eliminando intermediários, fazendo parte das suas estratégias de competição para a redução do risco e da incerteza, numa conjuntura de demanda decrescente.

Podem-se também encontrar casos concretos de arranjos entre indústria e seguro, como é o caso de firmas de benefícios farmacêuticos nos Estados Unidos (pharmacy benefit managers, PBM s) onde, a partir das iniciativas defarmáciase M COs (managed care organizations) se observou, nos anos 1990, a integração das maiores firmas de PBM com grandes indústrias farmacêuticas ${ }^{40}$.

A financeirização não seria enten dia, apenas, enquanto predominância, na dinâmica da acumulação, de interesses de financiadores privados, no caso, seguros de saúde. De acordo com entendimento original de capital financeiro ${ }^{26,41}$, essa definição contempla a idéia da junção entre 0 capital industrial e o mercantil bancário, a partir de uma grande concentração de capital e formação dos oligopólios, que passam a se tornar as instituições econômicas dominantes. A atualização desse conceito implica, certamente, na ampliação do lado mercantil bancário dessa relação para as novas instituições e instrumentos deacumulação financeira, como os fundos de investimento e os fundos de pensão.

No entanto, o segmento produtor de bens do complexo produtivo da saúde não deve ser negligenciado na análise da acumulação intrasetorial e global. Uma das dimensões que deve ser especialmente considerada é a importância atual da conta de serviços. Essa importância é particularmente significativa para as economias capitalistas centrais em função dos dividendos cobrados a título de direitos de patentes, licenciamentose direitos depropriedadeintelectual, pela centralização da pesquisa e desenvolvimento e conseqüentes inovações. Não se pode desconsiderar a observação de Harvey ${ }^{42}$ de que, possivelmente, virão das indústrias de bens de saúde norte-americanas (biotecnologia e equipamentos) novas ondas de inovação e de lucros extraordinários. Temporão e Gadel ha ${ }^{43}$, nesse sentido, afirmam claramente que o complexo industrial da saúde está entre as áreas com maior gasto mundial em pesquisa e desenvolvimento e, no Brasil, a cadeia produtiva da saúde representa, hoje, 6 a $7 \%$ do PIB, sendo que o segmento industrial gera 300.000 empregos diretos.

\section{À guisa de epílogo}

A constituição de um complexo médico-industrial-financeiro, no qual o processo de concentração e financeirização permeia todo o setor, mantém a importância do segmento industrial, no qual as maiores empresas do segmento saúde estão integradas aos grandes oligopólios financeiros internacionais. Considerando a sua capacidade de extrair mais-valia nos setores competitivos na economia ${ }^{26}$, induz-se, também, a concentração do segmento financiador e prestador de serviços de saúde, visando potencializar sua capacidade de negociação. Porém, os mecanismos da financeirização permitem, para o grande capital, a constituição de grupos com sinergias na acumulação entre o lado industrial, financeiro e de prestação de serviços, possibilitando atenuar a disputa pela mais-valia, concentrando-a no interior do grupo financeiro. No caso dos seguros e das indústrias relacionadas aos bens de saúde que se encontram entre os principais setores de acumulação ${ }^{44}$, não é exagero pensar que as principais empresas operem de modo integrado. 
Com isso, de fato, sedimenta-se o papel do seguro como crédito, em última análise, ao consumo industrial, Sendo, esta última afirmação, uma hipótese de trabalho, um passo à frente da análise das relações existentes no interior do complexo produtivo da saúde, não partiria, apenas, dos mercados mas, também, dos grandes grupos financeiros, que envolvem as principais empresas mundiais do setor e suas estratégias.

A tendência à manutenção de uma inflação médica poderia estar relacionada à criação e re criação de necessidades sociais de consumo, através da identificação entre produtos e estilos de vida, inovações e gastos maciços em propaganda. A securitização dos riscos deerro de diagnóstico eterapêutica, especialmente, através de seguros contra responsabilidade civil, também alimenta a espiral inflacionária. Finalmente, não sem menos importância, a operação da estrutura produtiva impõe a necessidade de vigilância e controle dos financiadores sobre os prestadores, induzindo a elevação de custos administrativos.

Cabe indagar se essas tendências de inflação de custos crônicas na saúde seriam estruturalmente contrárias aos interesses do setor segurador. Isso, em geral, se admite e conduz a depositar nas empresas desse setor uma capacidade de dotar os serviços de saúde de uma maior racionalidade. Como ganho comercial, interessa ao seguro absorver uma parte da mais-valia do setor serviços, produzida nesta esfera ou apenas parcialmenteretida na comercialização das mercadorias industriais relativas ao setor saúde. Como capitalista financeiro, no entanto, o seguro, ganhando nessa margem prêmios/sinistros (ganho comercial), não teria qualquer contradição, a princípio, em se mantendo a margem, também ganhar na massa (volume de prêmios), a ser aplicada nos circuitos de valorização financeira. No limite, portanto, da renda das famílias e gastos das empresas com seus empregados destinados à manutenção e reparação da saúde, o seguro se beneficiaria, não sem contradições, com o padrão atual deincorporação tecnológica no setor saúde, e com os custos crescentes. Caberia, então, à indústria de bens de saúde transformar suas mercadorias em necessidades sociais de consumo.

Diante disso, uma investigação sobre os padrões atuais de acumulação no setor saúde que permita estabelecer se as ten dências serão contencionistas ou expansionistas da inflação médica, e os papéis específicos de cada segmento, seguro, indústria ou serviços, deve levar em conta as tendências gerais da primeira década do século XXI. A maisfundamental dastendênciasacima mencio- nadas envolve a financeirização, não significando, de forma linear enecessária, o fortalecimento do lado médico-financeiro do complexo.

No caso dos serviços de saúde, podemos encontrar, segundo Baumol ${ }^{32}$, tanto setores "estagnados", de baixa produtividade do trabalho, quanto setores "progressistas", que têm passado por intensa introdução de maquinaria, concentração dos meios de produção e implementação demétodos gerenciais padronizados. As vias distintas de acumulação de capital poderiam trazer como conseqüência o fortalecimento de determinadas frações empresariais e uma maior heterogeneidade dos serviços privados de saúde.

As novas características da grande empresa,

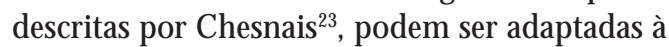
realidade do mercado de serviços pessoais, em quea proximidadeé um elemento fundamental. Assim, torna-se possível conciliar a centralização do capital e da tecnologia e a descentralização de partes do processo de produção, como éo exemplo significativo das empresas de exames de patologia clínica com suas redes descentralizadas de coleta e realização de alguns exames padronizados nos kits diagnósticos. A eficiência destes processos tem sido um elemento que impulsiona hospitais e outros estabelecimentos de saúde a optarem por tercei rizar estes serviços para grandes empresas, substituindo os antigos laboratórios próprios. $\mathrm{Na}$ área do diagnóstico por imagem, ocorrem processos semelhantes, percebendo-se uma tendência a fusões e aquisições entre esses dois segmentos da diagnose médica.

Nesse quadro, a regulação, em particular, do setor saúde, se torna mais complexa porque envolve pluralidade deagentes, relacionando-se, ao mesmo tempo, à política industrial, financeira e de serviços pessoais, todas permeadas pelas específicas normas éticas referentes à interven ção sobre a vida humana.

A capacidade de regulação pública, portanto, torna-se mais reduzida com a formação dos grupos financeiros. Sucessivas estratégias de transformação dos modelos de prestação do cuidado a partir do questionamento das necessidades de consumo criadas pela indústria são contrabalançadas pela sua capacidade de cooptação dos prestadores de serviços de saúde, inclusive através da subsunção das evidências médicas ao interesse das grandes empresas.

A manuten ção das relações atuais no interior do complexo médico-industrial-financeiro não permite vislumbrar perspectivas otimistas no tocante à presença de uma inflação médica crônica. Esse quadro reforça a necessidade de apro- 
fundar eatualizar a reflexão do caráter específico das transformações contemporâneas desse complexo que têm no segmento de serviços um importante vetor de mudança.

\section{Colaboradores}

MFS de Andreazzi e GEM Kornis participaram igualmente de todas as fases da elaboração do artigo.

\section{Referências}

1. Robinson JC. The Commercial Health Insurance Industry in an Era of Eroding Employer Coverage. Health Affairs 2006; 25(6):1475-1486.

2. Waitzkin HA. Marxist view of health care. Ann Int. M edicine 1978; 89:264-278.

3. Relman AS. The new medical-industrial complex. N. Engl. J. Med. 1980;303(7): 963-970.

4. Cordeiro HA. A indústria da saúde no Brasil. Rio de Janeiro: Graal; 1980.

5. Cordeiro HA. 0 complexo produtivo da saúde. [M imeo 2006]

6. Ocké-Reis CO, Andreazzi M FS, Silveira FG. 0 mercado de planos de saúde: uma criação do Estado? R. Econ. Contem. 2006; 10(1):157-185.

7. Levit KR, Cowan CA, Lazenby HC, MCDonnell PA. National health spending trends, 1960-1993. Health Affairs 1994; 13(5): 14-31.

8. Vianna CM M. Estruturas do sistema de saúde: do complexo médico-industrial ao médico-financeiro. PHYSIS 2002; 12(2):175-190.

9. Gadelha CAG. O complexo industrial da saúde e a necessidade de um enfoque dinâmico na economia da saúde. Cien Saude Colet 2003; 8(2):531-535.

10. Gadelha CAG. Desenvolvimento, complexo industrial da saúde e política industrial. Rev. Saúde Publica 2006; 40 (N Esp):11-23.

11. Albuquerque EM, Cassiolato JE. As especificidades do sistema de inovação em saúde. Revista de Economia Política 2002; 22(4):134-151.

12. Albuquerque EM, Souza SGA, Baessa AR. Pesquisa e inovação em Saúde: uma discussão a partir da literatura sobre economia da tecnologia. Cien Saude Colet 2004; 9(2):277-294.

13. Guimarães R. Health research in Brazil: context and challenges. Rev. Saúde Pública 2006; 4(N Esp):3-10.

14. M agalhães LCG, Leal JC, Safatle LP, Aurea AP, Tomich FA, Silveira FG, Barbosa LC, Ribeiro de Castro B. Estratégias empresariais de crescimento na indústria farmacêutica brasileira: investimentos, fusões e aquisições, 1988-2002. Rio de Janeiro: IPEA; 2003. [Texto para discussão no 995]

15. Negri B, di Giovanni G. Brasil. Radiografia da Saúde. Campinas: Instituto de Economia da UNICAM P/ Ministério da Saúde; 2001.

16. Hasenclever L. Diagnóstico da indústria farmacêutica brasileira. Rio de Janeiro: UNESCO/Instituto de Economia da UFRJ; 2002. 
17. Scandlen G. Consumer-driven Health Care: Just a Tweak or a Revolution? Health Affairs 2005; 24(6):1554-1558.

18. M erhy EE. Saúde, a cartografia do trabalho vivo. São Paulo: Hucitec; 2005.

19. Geyman JP. The corporate transformation of medicine and its impacts on costs and access to care. JABFP 2003; 16(5):443-454.

20. Andreazzi MFS. Teias e tramas. Relações púbico-privadas no Brasil nos anos 90 [tese]. Rio de Janeiro (RJ): Instituto de Medicina Social, UERJ; 2002.

21. Kornis GEM. Entre o futuro do capitalismo e o capitalismo do futuro: a long and winding road. São Paulo em Perspectiva 1998; 12(2):92-98.

22. Marx K. O capital: Livro 3 - 0 processo global da produção capitalista. São Paulo: N ova Cultural; 1988.

23. Chesnais F. A mundialização do capital. Rio de Janeiro: Xamã; 1996.

24. Dupas G. Economia global e exclusão social. Pobreza, emprego, Estado e o futuro do capitalismo. São Paulo: Paz e Terra; 1999.

25. Hilferding R. El capital financiero. Madrid: Editorial Tecnos; 1973.

26. Chesnais F. O capital portador de juros: acumulação, internacionalização, efeitos econômicos e políticos In: Chesnais F. A finança mundializada: acumulação, internacionalização, efeitos econômicos e políticos. São Paulo: Boitempo Editorial; 2005. p. 35-67.

27. Plihon D. As grandes empresas fragilizadas pela finança. In: Chesnais F. A finança mundializada: acumulação, internacionalização, efeitos econômicos e políticos. São Paulo: Boitempo Editorial; 2005. p. 133-151.

28. Fernandes AC, Lima JPR. Clusters de serviços: contribuiç̧ões conceituais com base em evidencias do pólo medico de Recife. Nova Economia 2006. 16(1):11-17.

29. Kon A. Economia de serviço - teoria e evolução no Brasil. Rio de Janeiro: Elsevier; 2004.

30. Baumol WJ. Macroeconomics of unbalanced growth: the anatomy of urban crisis. American Economic Review 1967; 57(3):415-426.
31. Baumol WJ, Blackman SAB, Wolff EN. Unbalanced growth revisited: asymptotic stagnancy and new evidence. The American Economic Review 1985; 75(4):806-817.

32. Gadrey J. L' économie des services. Paris: Éditions La Découverte; 1996.

33. Hardt M, Negri A. Império. Rio de Janeiro: Record; 2001.

34. Horta MH, Souza CF, Waddington SC. Desempenho do setor de serviços no mercado internacional. Rio de Janeiro: IPEA; 1998. [Texto para discussão $\left.n^{\circ} 600\right]$

35. Adlung R, Carzaniga A. Health services under the General Agreement on Trade in Services. Bull WHO 2001; 79(4): 352-364.

36. Marx K. Teorias sobre a mais valia. Rio de Janeiro: Civilização Brasileira; 1980.

37. M arx K. Capitulo VI Inédito de O Capital. São Paulo: Editora M oraes Ltda; 1969.

38. Silva e Meirelles D. O conceito de serviço. Revista de Economia Política 2006; 26(1);119-136.

39. Possas ML. Dinâmica e concorrência capitalista: uma interpretação a partir de M arx. São Paulo: Hucitec; 1989.

40. Grabowski H, Mullins D. Pharmacy benefit management, cost-effectiveness analysis and drug formulary decisions. Soc. Sci. M ed. 1997; 45(4):535-544.

41. Lenine VI. Imperialismo, fase superior do capitalismo. In: O bras Escolhidas, Tomo I. Lisboa: Editorial Avante; 1977. p. 576-671.

42. Harvey D. 0 novo imperialismo. São Paulo: Loyola; 2005.

43. Temporão JG, Gadelha CAG. A saúde em novo modelo de desenvolvimento. Folha de São Paulo, 2007 M ai 27; p. A3.

44. Navarro V. Dangerous to your health. Capitalism in Health Care. New York: Monthly Review Press; 1993.

Artigo apresentado em 04/06/2007

Aprovado em 28/02/2008 